\title{
Wo drückt Ihre Rheumapatienten der Schuh?
}

Geeignetes Schuhwerk ist bei Patienten mit rheumatoider Arthritis ebenso wichtig wie bei Diabetikern. Damit die Patienten mit ihrem orthopädischen Modell zufrieden sind, muss eine ganze Reihe von Faktoren „passen".

Patienten mit rheumatoider Arthritis (RA) haben ein besonders hohes Risiko, mit ihrem Schuhwerk „in Konflikt" zu geraten: Das hängt mit rheumatischen Fußdeformitäten zusammen, die leicht zu lokalen Drucküberlastungen führen können, aber z.B. auch mit der Einnahme von Methotrexat, welche über längere Zeit Hautatrophie und Polyneuropathie begünstigt. ( $\bullet$ Abb. 1)

Solche Probleme müsse man behandeln "wie einen diabetischen Fuß", mahnte der Rheumachirurg Prof. Dr. Ralph Gaulke von der Medizinischen Hochschule Hannover beim Rheuma-Update. „Die Patienten merken nicht, wenn sie sich wund gelaufen haben." Auch Rheumatiker sollten daher zur täglichen, mithilfe eines Spiegels durchgeführten Fußvisite angehalten werden. Dies diene dazu, Rötungen, die auf eine beginnende Ulzeration hinweisen, frühzeitig zu erkennen.

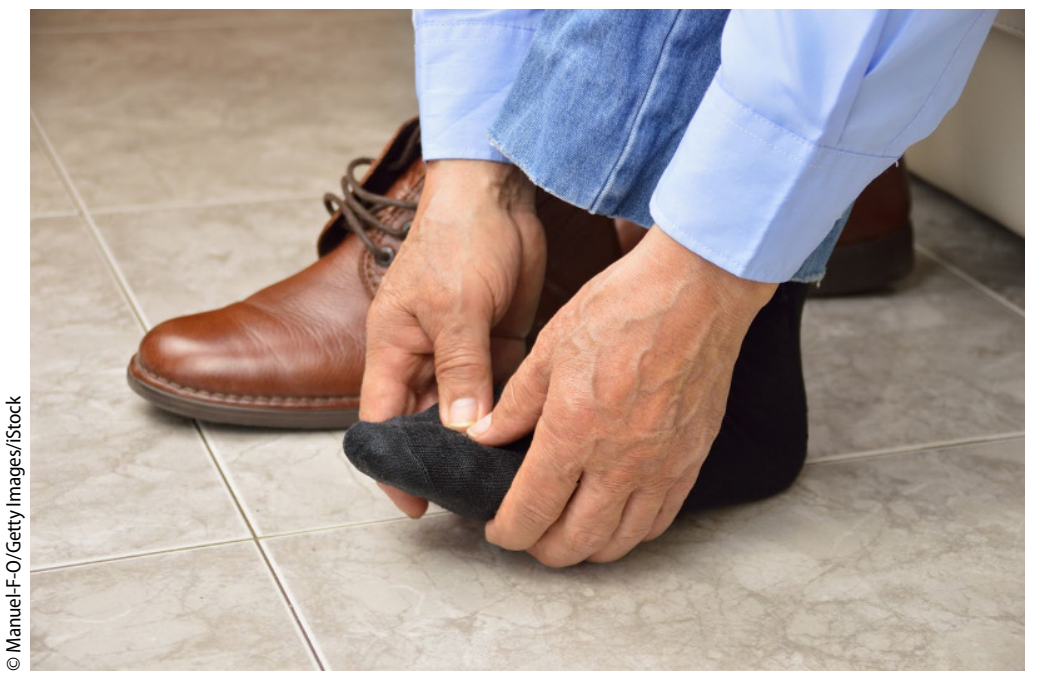

Abb. $1 \Delta$ Rheumatische Fußdeformitäten können leicht zu lokalen Drucküberlastungen führen

\section{Individuelle Beratung}

Gaulke zählte auf, welche Voraussetzungen orthopädisches Schuhwerk speziell bei RA-Patienten erfüllen sollte:

- Um zu verhindern, dass lokale Druckstellen entstehen, sollte auf weiches, nahtfreies Obermaterial geachtet werden.

- Länge und Weite des Schuhs müssen ausreichen dimensioniert sein.

- Auf Absätze sollte man verzichten, um die Vorfußbelastung so gering wie möglich zu halten.

- Da RA-Patienten häufig auch Arthrosen an Hüft- und Kniegelenk aufweisen, sollte man darauf achten, dass der Schuh nicht zu schwer ist.

- Für Patienten mit Handdeformitäten sollte man anstelle von Schnürsenkeln eher einen Klettverschluss wählen.

Bei der Sohlenform komme es nicht nur auf einen guten Abrolleffekt an,

Quelle: Dr. Elke Oberhofer, SpringerMedizin.at, basierend auf: Rheuma Update, 12.-13. März 2021 Vortrag von R. Gaulke: "Orthopädische Rheumatologie" betonte Gaulke: Zwar sei eine Mittelfußabrollsohle wegen des kurzen Hebels, der auf das obere Sprunggelenk wirkt, von der Gangdynamik her besonders günstig. Allerdings gehe die so erreichte kürzere Sohlenbelastung auf Kosten der Stabilität: „Bei Patienten mit Gangunsicherheit sollte man die Vorfuß- gegenüber der Mittelfußabrollsohle präferieren“, riet der Experte.

\section{Auch die Optik zählt!}

In der Praxis begegnet Gaulke häufig dem Problem, dass die Optik für die Patienten mehr zählt als Bequemlichkeit. „In guter Absicht verordnetes teures orthopädisches Schuhwerk wird letztlich nicht getragen, weil es unattraktiv ist." Daher rät der Experte, zunächst „im Vertrauen“ persönliche Vorlieben zu erfragen: „Würden Sie überhaupt einen orthopädischen Schuh tragen? Muss er modern sein? Welche Farbe soll er haben?" Zur Beratung gehöre auch die Frage nach der beruflichen Tätigkeit und dem dafür erforderlichen Schuhwerk. Und schließlich müsse darauf geachtet werden, dass der Schuh für den Patienten auch erschwinglich ist.

Hinweis des Verlags. Der Verlag bleibt in Hinblick auf geografische Zuordnungen und Gebietsbezeichnungen in veröffentlichten Karten und Institutsadressen neutral.

rheuma plus $2021 \cdot 20: 190$ https://doi.org/10.1007/s12688021-00435-w (c) Springer-Verlag GmbH Austria, ein Teil von Springer Nature 2021 